\title{
PD Pattern Analysis During Induced Test of Large Power Transformers
}

\author{
Edward Gulski, Hendrik P. Burger \\ Deltit Liniversity of Tetintelogy \\ High wol tage Labolatory \\ Delit, The Nedlerlands
}

George H. Vaillancourt

Hydro Quélwec High Voltage laboratory IRFQ, varemes, Qucbes, Canadia

\section{Roger Brooks}

Haefely Trendh $A \mathrm{G}$

lettrex Insteuments Division

Dietiknn-Zuridh, Switzethand

\begin{abstract}
The partial discharge (ro) neasurements on power transformers are studied with a view toward discrimination and slassification of different disclarge sources. For this purpose digital analysis is applied to power transformers and reactors going through acceptance testing. Furthermore, based on these measurements, PD databases have been developed to support the discharge evaluation during induced voltage tests of transformers. Using this technique, a clear distinction is possible between transformers showing different discharge behavior.
\end{abstract}

\section{INTRODUCTION}

I $\mathrm{T}$ is known that based on $1 \mathrm{~h}$ induced voltage test of a power transformer, important conclusions are made regarding insulation conditions of the test object. It is also known that such HV apparatus is not discharge free. On the contrary, a certain lovel of discharges $\angle 500 p C$ is allowed, and most interpretation of the measuring restils depents on the subjective opinion of test engineers. Basically during an inducet test two types of discharges may occur: discharges related to the setup (floating $\mathrm{H} v$ clectrodes or connections, ungrounded parts, efc.) and Pu related to internal sources in the insulation of a test object.

Due to the fact that testing power transformers with rated power of $>200$ MVA requests quite large test atcas with test facilities to $1 \mathrm{WV}$, even very careftul laboratory handling cannot exclude the first type of discharges. Searching for discharge sources and their location within the setup before starting ind uced voltage test in stich laboratories may be time-consuning. Moreover during entanced voltage level some discharges may be incited first at the higher woitage level, It is therefore of importance to compare the $\Gamma D$ pattern befor, during and after this period (see Figure 1). With the advent of digital processing (see Figure 2), the task of data acquisition and evaluation now can be performed efficiently [1-4]. In particular the time behavior of po patterns, as well $P D$ pattern discrimination and classification with regard to the location of the internal and external discharge sources can be supported. The main goal of this study was to investigate the possibilities of digital processing to support PD pattern recognition during induced voltage tests of large power transformct's.

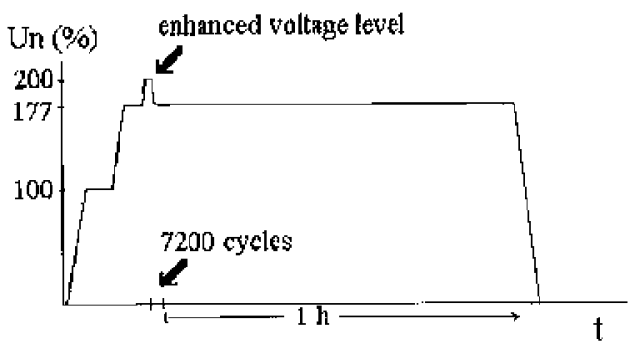

Figure 1. The time curve of test voltage during induced voltage test.

\section{PD PATTERNS OF TEST SETUP}

Several realistic problents were created artificially in the setup and the patterns were studied using a digital pD analyzer (TEAS-D) [2]. Here two examples will be discussed in detail, and compared to other problens. In Figure 3 two PD patterns are shown. One obtained from an aluminum rod extending from a $\mathrm{HV}$ sphere on an aitotranstormer and the other one obtainet of discharges occurring on a metal ring from a cotton strap extending from a HV sphere. It follows lrom this Figure that both sources are characlerized by similar shape of PI patterns unless there are enormous difference in the $P D$ amplitude, which are located at different phase positions of the power frequency. To discriminate befween these twro setup faults and other similar problems which are quite realistic for large laboratorics, fractal analysis can be applied [3]. In Figtre 4 an oxample is shown of this analysis. It follows from this Figure that such a discrimination tool provides distinction between 
different groups of defects

1. defect $3 \mathrm{~ms}$. defect 4 ,

2. defects 1 and 5 us. defect 4 ,

3. defect 1 and $5 \mathrm{dg}$, defect 3 ,

4. dc.
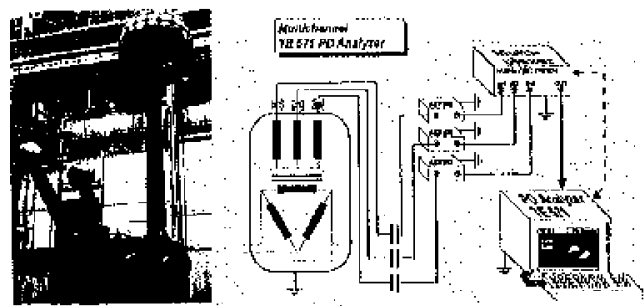

Figure 2. Off-line pu analysis of power transformers: (left) photograph of a 370 MVA auto tronsformer under test, (righe) schenatic diagram of confentional PD moasuring system conposed of a multi-channel ['D analyzer and coupling devices each connected to Hy busting measuring screens of the test object.

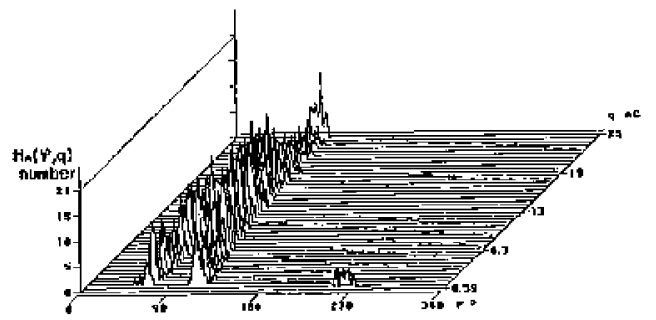

Figure 3. Example of $H_{n}(\phi, \phi)$ PD patten as obserwed (top) at $100 \mathrm{kV}$ test woltage on fin aluminum rod extending fiom the HV sphere of a $370 \mathrm{MVA}$ Auto-Tiansformer, (bottom) at $600 \mathrm{kV}$ on a metal ring form a cotton strap which was left in the sphere and extending from it on the top of a $55 \mathrm{MV} /$ reactor,

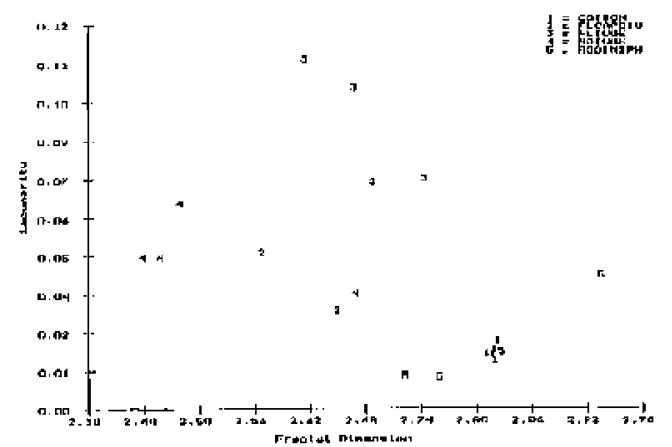

Figure 4. Result of fractal analysis as applied to six different artificially made in a sctup discharge sources. 1: metal ing with a cotton strap cxtending from the $\mathrm{H} \checkmark$ sphere, 2: floating object near the test sumple, 3 : floating shielding electrode, 4: no shielding electrodes on the test object, and 5 ; an aluminum rod extending from the IIv sphere.

The fact that no distinction is possible botween defect 1 (metal ring extending form the HV sphere) and defect 5 (metal rod extending from HV sphere) can be explain by the fact that unless different sources in both cases the same type of defect was mentioned: sharp point on the Hv electrode.

\section{REGULAR PD PATTERNS IN LARGE POWER TRANSFORMERS}

IE is known from transformer tests that during an induced test a certain PD level is permitted. In particular the PD patterns which may occur during flis test are analyzed as a lunction of time and the behavior of the magnitude is observed carefully with regard to their origin (see Figure 5). In addition, different Pu distribution can also be processed to describe the PD patterns. In the following a few typical l'D pattents are shown, which wetc observed on objects without any insulation problems (see Figures 6 to 8). A single PD pattern, as represented by different statistical distributions, can be processed by special tools to extract the characteristic properties [2]. To discriminate between series of such fingorprints statistical processing can be applied.

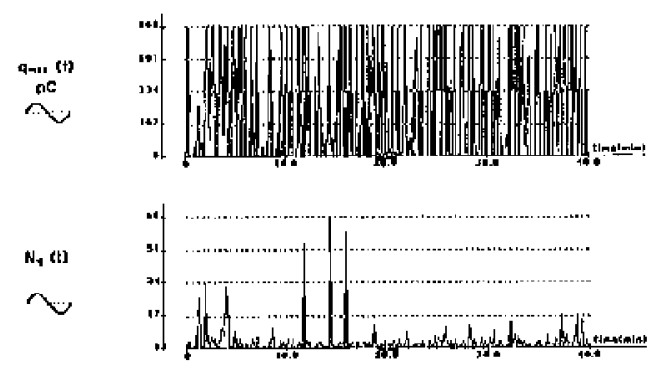

Figure 5. Typical example of ${ }^{x} \cup$ quantities $q$ tmax $(t)$ and $N_{n}(t)$ as obsarwed at $1.7 U_{\mathrm{n}}$ during $40 \mathrm{~min}$ induced test of a $47 \mathrm{MVA}$ 3-phase trantsJormer.

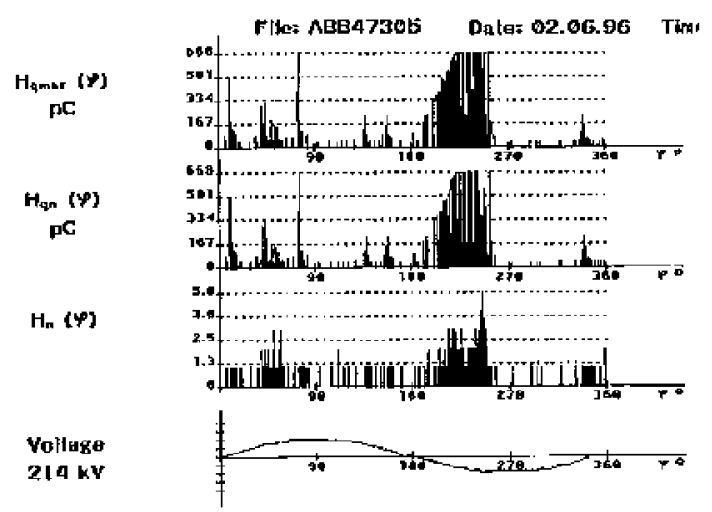

Figure 6. Typical example of phase-resolved distribulions as observed during 2 min induced test of a $47 \mathrm{MVA}$, 3-phase transformer.

In Figure 9 an example of comparison to other samples of power transformers is shown. Most of the samples with $90 \%$ recognition were characterized by the fact that no problems or irregularitios were observed duting induced voltage level (exception has to be made in the case of 55 MVA reactor and 203 MVA transformer, see next Section). It follows from this classification diagram that the dischanges observed in this particular 47 MVA 3-phase transformers are similar with probability of $>90 \%$ to other test objects which were $11 \mathrm{~b}$ god condition. This result is roasonable, since all these transformers were accepted after induced votage test. 


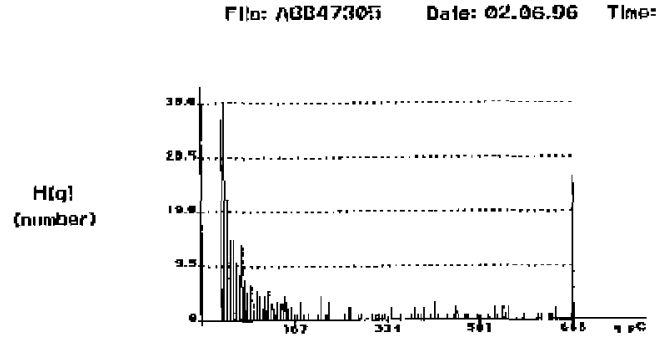

Figure 7. 'lypical example of 1 ) intensity distribution $H(q)$ as observed during 2 min lost of obects in rood condition; 17 MVA 3 phase translormer.

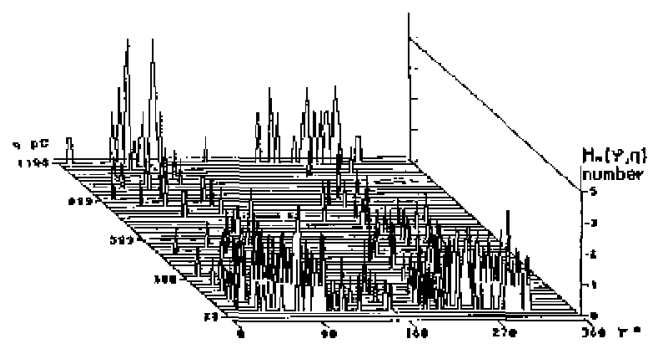

Figure 8. Typical example of $H_{n}(\phi, \gamma)$ Pu pattern is observed for a transformer in good condition; a 370 MVA autotansfomer. This pattern was also observed during the enhanced wolnge lowd test as well as after 1 li woltage test at $1.7 U_{n}$.

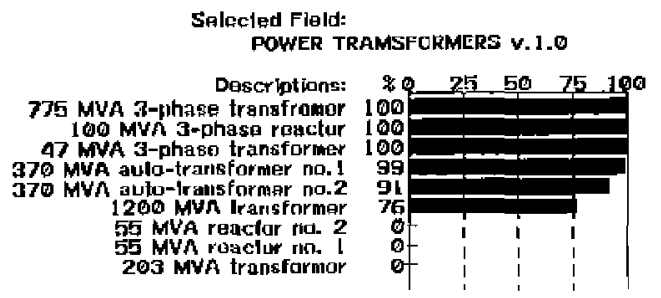

Figure 9. Recognition by a compuler-aided data bank 'Power Transformers $v 1,0^{\prime}$ of 113 pattens as observed for a 47 MV 3 3-phase transforner in a good shape. Typical is the overlap in the recognition with other test samples also showing regular PD patterns.

\section{IRREGULAR PD PATTERNS IN LARGE POWER TRANSFORMERS}

In the following, two examples will be discussed where additional discharges were observed (1) after enhanced voltagc level of discharges in the comnectors of a 370 autotransformer, (2) internal discharges on a damaged screen inside a $55 \mathrm{MVA}$ reactos: It follows from Figure 10 that in contrase to ligure 8 the PD pattern has been changed permancutly due to increased voltage stress. In Figure 11 an interesting cxample is shown, where the presence (cases 3 and 4 ) and the absence (cases 1 , 2 and 5) of a particular defect are visible by fractal analysis plotting. In particular the fractal analysis shows that the inception of setup discharges as well as the effect of removing the discharges source (see Figure 12) can be observed in the behavior of tractal paraneters. As shown in this cxample, the additional information as obained from fractal analysis can support the decision process during po testing and waluation of measuring results.
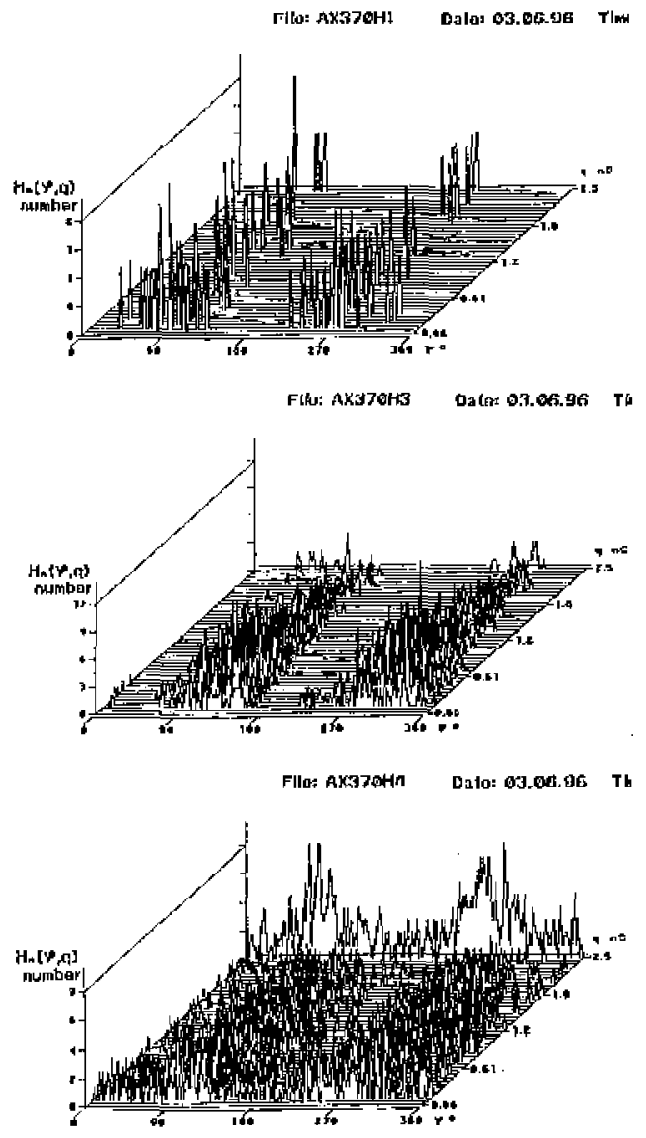

Figure 10. $H_{4}(\phi, q)$ po pattern as obseved before $(a)$, during $(b)$ and after (c) enhanced voltage level of a $370 \mathrm{MV} A$ autotrinsformer.

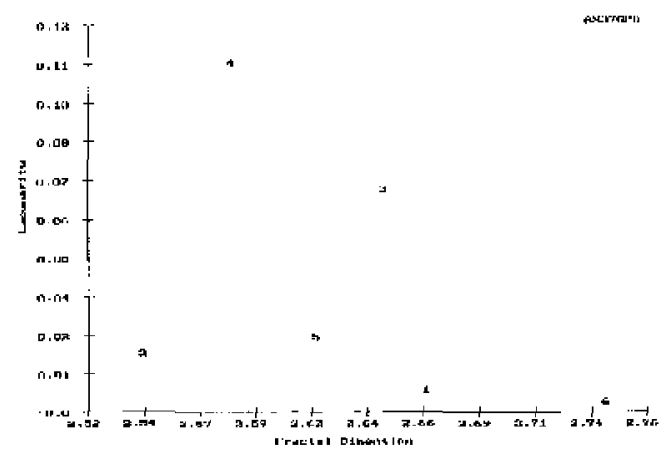

Figure 11. Result of fractal antalysis as applied to six PD tests of a 370 MVA antotransformer. 1 and 2: regular PD pittern before conlanced voltage level, 3: irregular. Fo pattorn dilring collanced voltage level (igniIjon of discharges in the setup), 4: PD test after enhanced voltage level (discharges in the setup), 5 and 6: PD lese after renoving of discharge sonce.

In Figute 13 the l'D intensity is shown from an induced test of a 55 MVA ractor containing internal dischirges on a damaged screen. In Figure 14 the pliase-resolved $3 \mathrm{D}$ distribution is shown. As compared to l'l patterns from Section 3 it is evident that discharges, caused by specific faults like a damaged screen, are characterized by specific pat- 


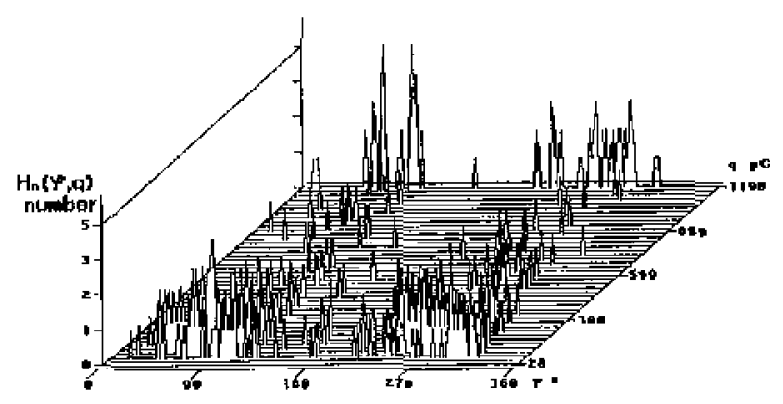

Figure 12. $H_{n}(\phi, q)$ PD pattern of a 370 MVA autotransformer obscrved after enhanced voltage level, and after removing the Plo source in the setup which was ignited during enhanced voltage lovel, see Figures 10 and 11 .

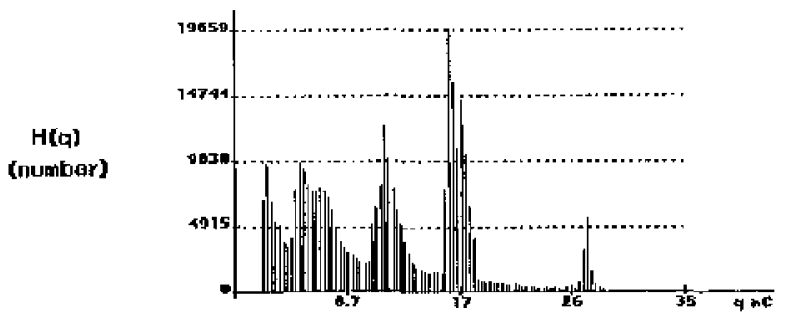

Figure 13. l'b intensily distribution $I I(q)$ as observed within $2 \mathrm{~min}$ for a 55 MVA reactor containing discharges on a dantaged screcn inside the test objects.

torns. To describe these differences visual comparison of po patterns or numatic classification tools can be used (see Figure 15). Experience has been obtained during application of the following discrimination techniques: fractal analysis which is applied to evaluate the 3 dimensional phase resolved PD patterns; and tree structure which is based on group average analysis.

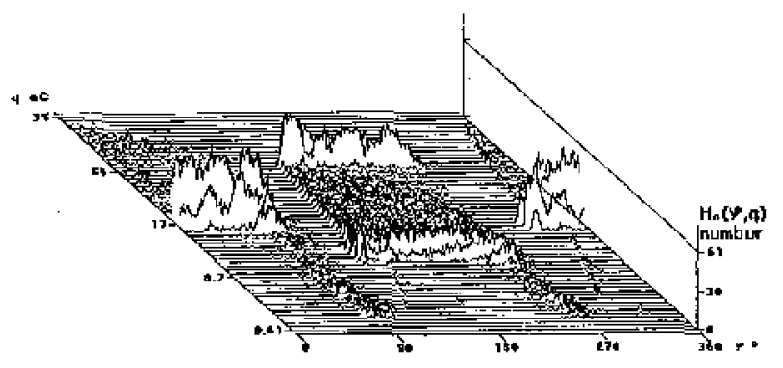

Figure 14. $H_{n}(\phi, q)$ po pattern as observed alter enhanced voltage level of a 55 MVA reactor containing Po on a damiged screen inside the tost object,

To evaluate a large number of fingerprints obained for several different TD sources or different types of transformers, or to investigate the clustering of the measuring results in order to discriminate betwoon different discharges the 2nd method (tree structure) is suitable.

To investigate the differences bothren different PD neasurcuncnts or discharge sources as obtained for the same type of transfornec; the first

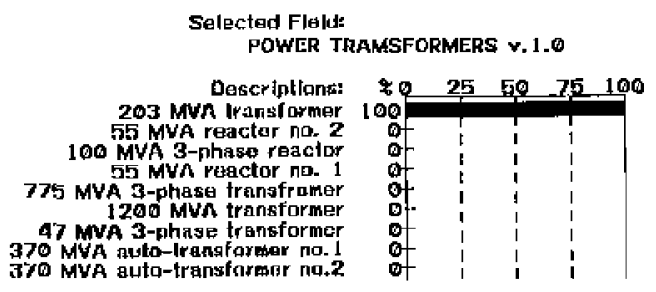

Figure 15. Recognition by a computer-aided data bank Power Transformers v1.0' of l'D pattorns as obserwed for a 55 MVA reactor containing I'] on a damaged screen inside the test object. In contrast to ligure 10 no resemblance was observed to other tests objects showing regular $P D$ patterns.

method (fractal analysis) scems to be promising.

\section{PD DATABASE FOR DIAGNOSIS SUPPORT}

When a mensurement is made on a power transformer, it can be compared to the l'D measurements obtained from such objects in the past (see Figure 16) which have been collected in a databasc. The previous Sccions have investigated the possibilities of digital processing to support Pu pattern recognition during induced voltage tests of large power transformers [4]. In the following, the importance of developing a $\mathrm{P}$. database to support l'D cyaluation is discussed on the basis of 80 measurements made on power transformers and reactors in the period of four years. These measurements were analyzod using statistlcal tools as discussed in $[2,5]$.

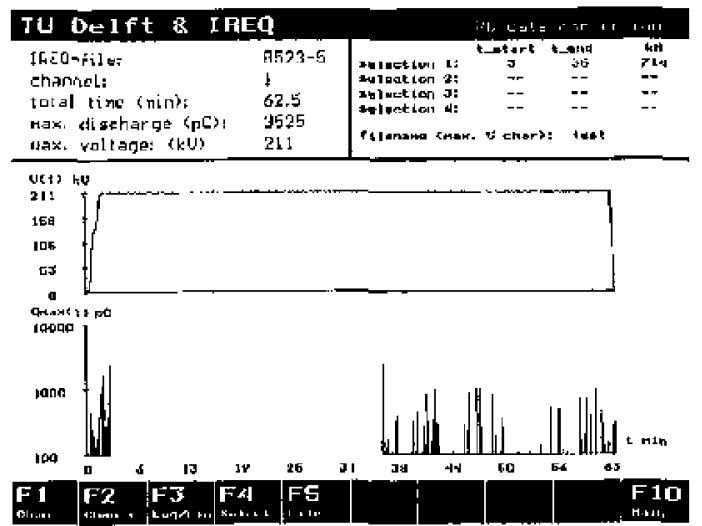

Figure 16. Moasuring data example of a $1 \mathrm{~h}$ induced voltage test of a power transformer. The marks are between 3 and 35 num and represent the fime sequence of (1) measuring data which were used in this particular case for further pol data base processing.

For rasons of clarity, the entire PD database has been divided into two separate parts. The first part has been made on the basis of moasurments made on reactors, whereas the second part concorns autotransformes and three-phase transformers only. The thain goal of this PD database was to answer the question about general trends in l'D patterns in the case of regular or irregular I'] patterns which occur during induced woltage test of power transformers and reactors.

$A$ data bank is well designed for chassification purposes if it produces a high similarity for one defect and a low one for all the others. If no 
classification can be made, it should produce a low similarity for all defects, Due to the fact that the user of a digital l'u detector type TF571 also can croate his own data bank, it was important to know how a well-designed data bank can be made.

For this purpose, several discrimination techniques can be used [5|. The main goal of all these methods is the recognition of cluster's without a priorj knowledge. This means that no labels indicating the membership of an individuat moastument to a particular cluster are present beforehand.

To analyre the measurements discussed in this report group average analysis technique was used [2]. Using this method discrimination between possible clusters can be made. In the case of several measurements cacl represented by a fingerprint this method examines the distances bewoen all fingerprints. Tline results of the analysis is a tree structure, which illustrates the relationships between individual fitgerprints, see ligure 18. The percentage scale in the lower part of this graphic shows the dissimilarity between fingerprints that were fused together:
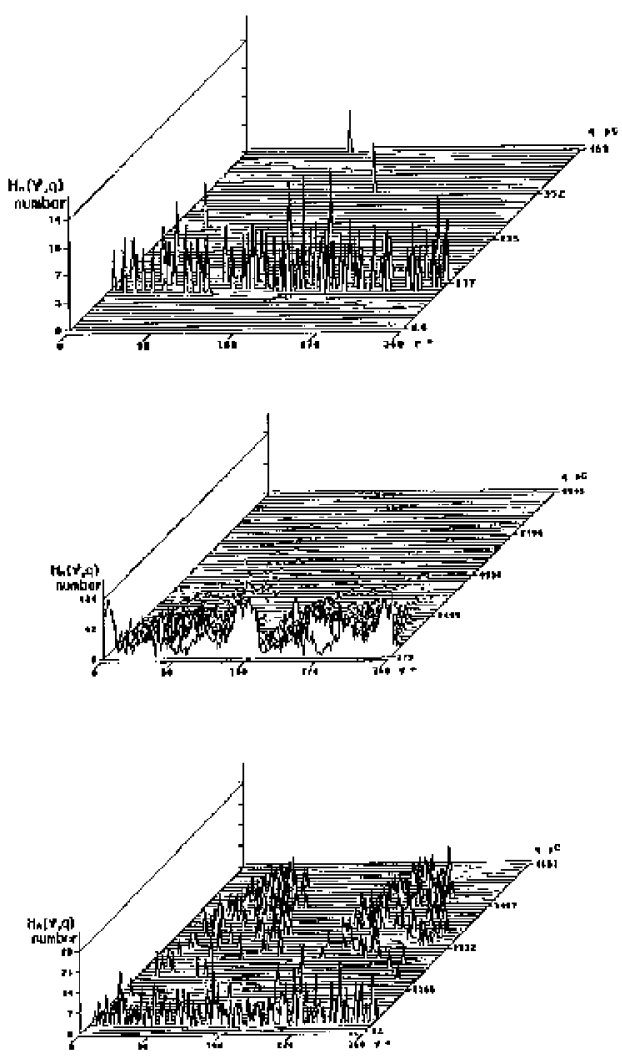

Figure 17. l'u pattern as observed for a transformes showing (top) regular l'D ovaluation regular. (nidd)e) irregular ['l) evaluation irregula:; (bottomil unknown Pr) (valuation unknown.

\section{EVALUATION CRITERIA FOR PD MEASUREMENTS}

When discharge data as measured during 1 h voltage application, using a multichannel system, is evaluated, the following two important

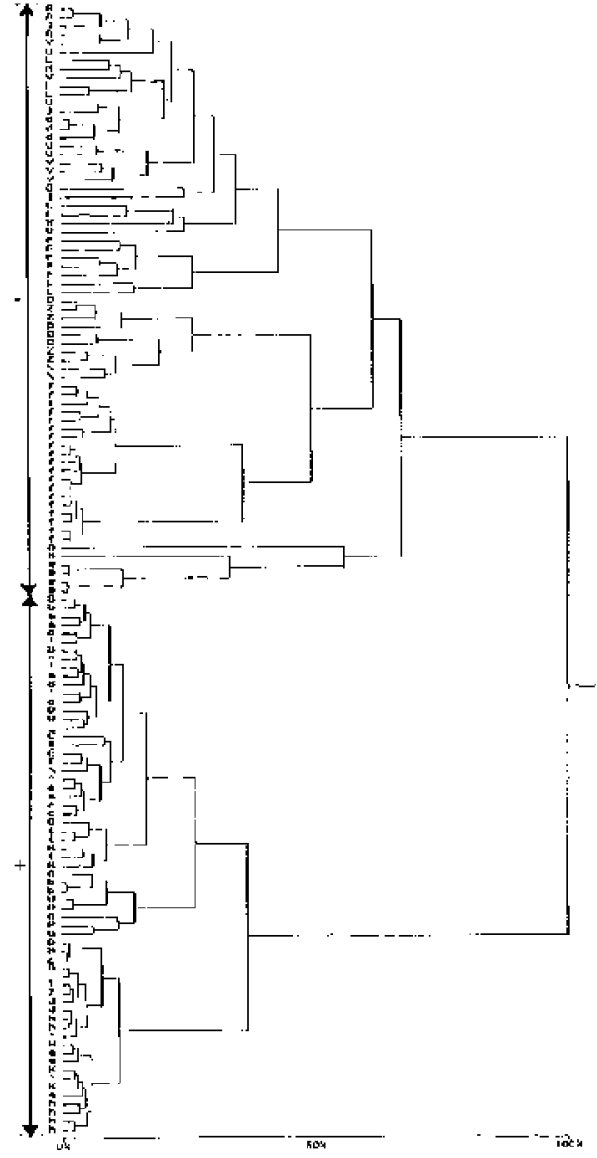

Figure 18. Result of clustor annlysis as applind to l'u pattens measured on 40 different power reactors.

points have to be considered.

\subsection{THE TIME SPAN OF A MEASUREMENT}

Comparing all mensuring data no uniform measuring time was used. A l'D measurement used in this evaluation may represent measuring data mensured only for a certain period in time on a certain channel of the test object. The duration of this time period may be different for ach test object. As a result this diversity in the acquisition time may influence the interpretation of particular $l^{3} \mid$ s patterns.

For cxample whon during an induced voltage test only a fow pulses oceur this can load to a difterent conclusion by analyzing the $\mathrm{PD}$ pattern from only one minute period and by analyzing $\mathrm{PJ}$ patterns from the 1 h test period.

\subsection{THE MEASURING CHANNEL}

As mentioned above, for one test object, measurements can be taken on a number of channels. It is known that in such a large test object as a power transformer cross-talk effects nuy occur between different chamels and that also multiple discharge phonomena in the test object are possible. 
Table 1. Four possible combinations of the two criteria and their cvaluation.

\begin{tabular}{|c|c|c|}
\hline $\begin{array}{c}Q m_{2} \\
m C\end{array}$ & $\begin{array}{c}\text { Int. } \\
\mathrm{y}\end{array}$ & Eval. \\
\hline$\leqslant 1$ & $\log w$ & rogulat + \\
\hline$\leqslant]$ & bight & tunknown \\
\hline$>1$ & $104 \%$ & unknown \\
\hline$>1$ & high & irregul|atrt - \\
\hline
\end{tabular}

As a result separate evaluation of po signals of a respective channeis would be necessary. In this sudy no distinction was made between test objects with one and more measuring chamels, Each PD pattern showing meastred data was evaluated with equal importance.

\subsection{DISCRIMINATION CRITERIA}

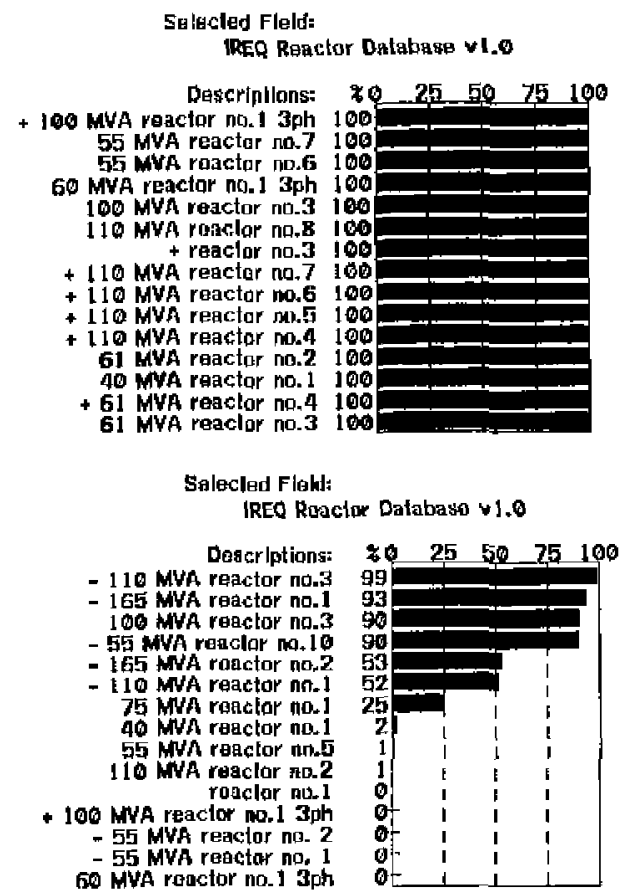

Figure 19. [ixamples of recognition to the reactor database (top) in case of an acceptable PD pattern, (bottom) in case of a PD defcet causing discharge $(+),(-), 0$ represents it test object in the databise characterized by a (regular), (irregular) (unknown) pattom.

No a priori knowledge was available about the 11sed IREQ PD testdata, of which the database is built. Therefore the data has been evaluated using the following two criteria: discharge magnitude, and discharge intensity.

In Figure 17(a) typical examples of 3-dimensional phase resolved PD patterns are shown. In particular the differences in lp magnitude as well as in the PD intensity are shown here. Based on this experience, the above mentioned criteria have been defined. For the first a level of $1 \mathrm{nC}$ has beon used, for the second criterion no quantitative level could be defined. As discussed in previous Sections, the liD patterns of power transformers have to be craluated on the base of experience. In
Table 2. List of power reactors (MVA and number) used for cluster analysis in Figure 18.

\begin{tabular}{|c|c|c|c|}
\hline Code & & VYN & No. \\
\hline$A$ & & $55_{1}$ & 4 \\
\hline [B & & $\mathbb{A}\{\}$ & 1 \\
\hline C & & 50 & 5 \\
\hline $\mathrm{D}$ & + & 100 & 2 \\
\hline F. & & 100 & 3 \\
\hline $\mathrm{F}$ & - & 100 & 1 \\
\hline $\mathrm{G}$ & + & $\tilde{0}$ & I \\
\hline [I & + & 艹 & 2 \\
\hline I & + & i) & 3 \\
\hline J & & 38.5 & 1 \\
\hline K & & 25 & 1 \\
\hline i. & $=$ & $19 \vec{i}$ & 1 \\
\hline $\mathrm{M}$ & - & 16 is & 2 \\
\hline $\mathrm{N}$ & & 61 & $z$ \\
\hline 0 & $1-$ & 110 & 1 \\
\hline $\mathbf{I}^{1}$ & & Fii & 6 \\
\hline$Q$ & & bis & 7 \\
\hline R & & 5 & 8 \\
\hline $\mathrm{S}$ & & 110 & 2 \\
\hline 'I' & & 75 & 1 \\
\hline $\mathrm{U}$ & & & 1 \\
\hline$y$ & - & & 2 \\
\hline$W$ & & $20 \%$ & 1 \\
\hline$x$ & - & 5,5 & 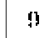 \\
\hline $\mathrm{V}$ & - & 5,5 & 10 \\
\hline 7 & & [i]. & 3 \\
\hline - & +1 & [i]. & 4 \\
\hline 1 & & 10 & L \\
\hline$\vdots$ & 1 & 210 & is \\
\hline$\tilde{i}$ & 1 & 210 & 4 \\
\hline- & + & 110 & 5 \\
\hline 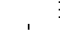 & + & 110 & is \\
\hline a & + & 110 & 7 \\
\hline b & + & & 15 \\
\hline f & & 110 & 8 \\
\hline $\mathrm{d}$ & - & 110 & 0 \\
\hline 0 & & 80 & .1 \\
\hline$f$ & 5 & 55 & 1 \\
\hline$g$ & -1 & 35 & 2 \\
\hline $\mathrm{h}$ & + & 100 & 1 \\
\hline
\end{tabular}

the following, four examples will be given, showing the four possible combinations, as listed in Thble 1.

In the example shown in Table 2 and Figure 18 two main groups can be observed. It follows that similar fingerprints will be connected at relatively low dissimilarity levels, while differing fingerprints will bo connected at relatively high dissimilarity levels. By cutting such a tree structure at a certain level, the data can he divided into different clusters.

Based on such clusters, reference data for a particular PD problem can defined in the P]) database [2]. The l'D database made for power reactors shows a clear separation between two clusters. The first cluster (-) contains measurements marked as 'bad' or 'umknown'.

The second cluster' ( + ) contains measurements kwaltated as 'good' or 'unknowr'. Both clusters also contain 'unknown' measurements. This category represents motsurements which are charackerized by low intensity discharges $>1 \mathrm{nC}$.

To draw any conclusion about these measurements mote background 


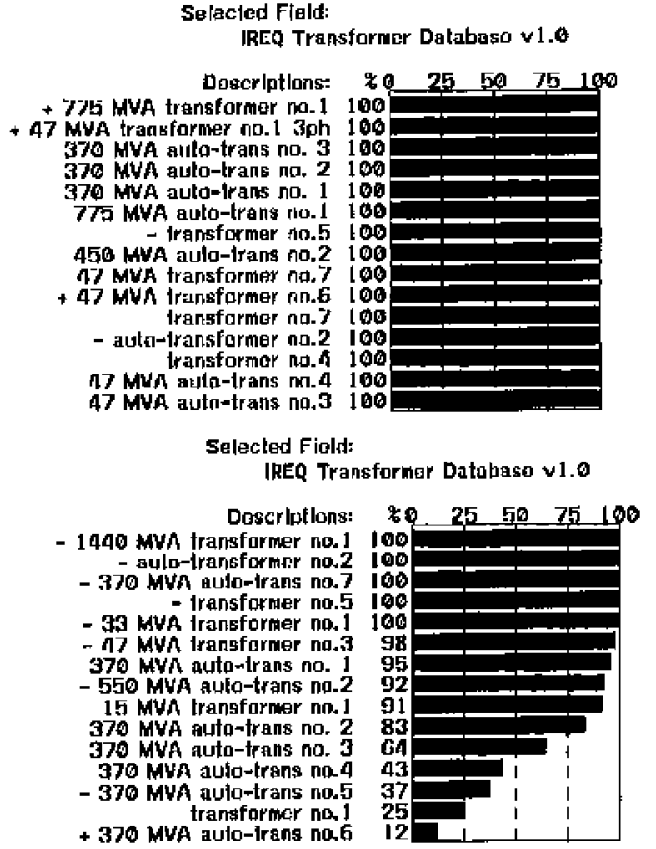

Figure 20. Examples of recognition to the transtormer reactor databnse (topt in casr of an acceptable PD pallern. (bolton) in case of an unaccept-

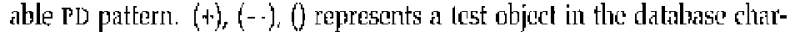
acterized by a (regular), (irregular) (unknown) pattern, $(f),(-), 0$ represents a tose olject in the database characterized by a (regular), (irregular) (unknown) pattem.

information would be necessary. Anyway due to the fact that "irregular' and 'tegulat' mensurements are clearly separated the prosence of 'unknown' data in both clusters is interesting and shall be investigated in more detail. In similar way l'b measurements on power transformers have been evaluated. Using clustering by means of tree analysis similar distinction has been observed between the first group $(+)$ and the second (-).

\section{USE OF THE PD DATABASE}

When a measurement has been made on a test object, it can be compared to the databasc, using elhe centour score method, available on the TF-571 PD analyzer. In the following four examples are given showing an application of both databases during classification of an unknown measurement. As observed in previous Sections, the recognition of an acceptable r's pattern by a database (Figure 19) gives a nultiple recognition for many cases. In most of these cases a low clischarge magnitude as well as a low discharge intensity was observed ( + ). No recognition of unacceptable l'D problems is found. When a typical defect is classified, recognition of only a few problems is found (Figure 20), most of which are unacceptable lo patterns.

\section{CONCLUSIONS}

$\mathrm{T}$ HE digital classification of PD patterns during induced voltage test of power transformers an be useful for the following purposes:

1. identification of discharges in the test setup,

2. analysis of changes in l'p behavior before, during and after the poriod of enthanced voltage level,

3. comparison of eD patterns of differenl transformers to identily the different discharge souires

4. Lo develop further a IPD database for power tramsformers the following has to be considered that a database should contain two types of information: PD patterns characteristic for this type of transtormers, and IPI patterns representing certain un-pormitted discharge sources.

Using digital processing of PD patterns distinction between different discharging test objects like power transforners and reactors is possible. Using this techniquc a discharge based decision supporting tool can be developed for induced voltage tests of power transformers and reactors.

\section{ACKNOWLEDGMENT}

The authors would like to thank ABB Varennes in Canada for supporting the experimental work.

\section{REFERENCES}

[1] C. 1. Willancowrt, R. Meurier, C. Jasmin, M. J. Lefebyse, C. Vaillancourt, "Newr Ireq Mutti-Channd PD Mcasurement System,", Jnt. Symp. on Dig. Tedh. in EIV Measurements, Toronto, Comadn, $199 \mathrm{~L}$,

(2) F. Gilski, "Digital Analysis of l'D", ILEE Trans. on D and F.I, Vol. 2, pp. 822-837, 1595.

[3] E. Gulski, II. I. Bueger, A. Ziejonka, R. Brooks, "Classification of Defects in HV Components by Fractal Analysis of PD Measurencents", 1996 JEFF. Anitual Report - Conference on Fl and Diestectric Flenomena, Sin Francisco, LSA, October 20-23, 1996. pp. 4k4. 4s8.

[4] A. Kivda, E.Culski, [n, Satisht, W. S. Zinengl, "The Use of Firactal Features for Recoggnilion of 3-D Lischarge Patterns", IEEF Trans, on D and EI, Wol. 2, pF. 889-892, 1995.

[5] A. Krivda, "Automaled Recognition of PD", IELE' 'Jrans. on D and El, Vol. $2, \mathrm{PP}$ 796-821, 1995

This paper is based on a presentation given at the 1997 Voln Colloguium on Partial Discharge Measurements, Como, Italy, 1997.

Mantersipt wats received on 24 April 1998 in final form 30 October 1999. 